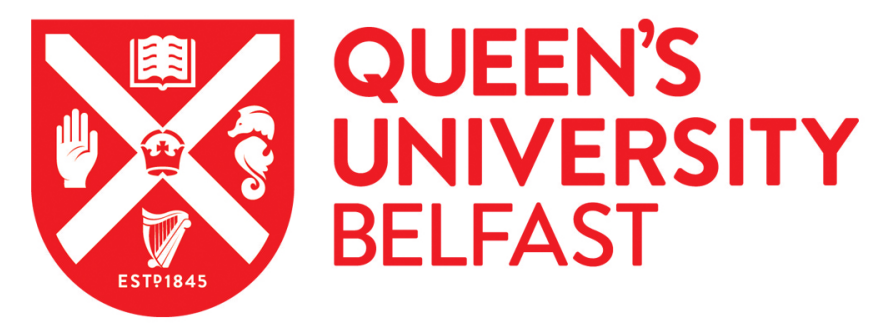

\title{
Mutations in the amino terminus of ANKH in two US families with calcium pyrophosphate dihydrate crystal deposition disease
}

Williams, C. J., Pendleton, A., Bonavita, G., Reginato, A. J., Hughes, A., Peariso, S., Doherty, M., McCarty, D. J., \& Ryan, L. M. (2003). Mutations in the amino terminus of ANKH in two US families with calcium pyrophosphate dihydrate crystal deposition disease. Arthritis and Rheumatism, 48(9), 2627-2631. https://doi.org/10.1002/art.11133

Published in:

Arthritis and Rheumatism

Queen's University Belfast - Research Portal:

Link to publication record in Queen's University Belfast Research Portal

\section{General rights}

Copyright for the publications made accessible via the Queen's University Belfast Research Portal is retained by the author(s) and / or other copyright owners and it is a condition of accessing these publications that users recognise and abide by the legal requirements associated with these rights.

Take down policy

The Research Portal is Queen's institutional repository that provides access to Queen's research output. Every effort has been made to ensure that content in the Research Portal does not infringe any person's rights, or applicable UK laws. If you discover content in the Research Portal that you believe breaches copyright or violates any law, please contact openaccess@qub.ac.uk. 


\title{
Mutations in the Amino Terminus of ANKH in Two US Families With Calcium Pyrophosphate Dihydrate Crystal Deposition Disease
}

\author{
Charlene J. Williams, ${ }^{1}$ Adrian Pendleton, ${ }^{2}$ Gina Bonavita, ${ }^{1}$ Antonio J. Reginato, ${ }^{3}$ \\ Anne E. Hughes, ${ }^{2}$ Shelly Peariso, ${ }^{1}$ Michael Doherty, ${ }^{4}$ Daniel J. McCarty, ${ }^{5}$ \\ and Lawrence M. Ryan ${ }^{5}$
}

\begin{abstract}
Objective. To analyze ANKH in families with calcium pyrophosphate dihydrate crystal deposition disease (CPPD) for disease-causing mutations.

Methods. Two US families (one of British ancestry and the other of German/Swiss ancestry) with autosomal-dominant CPPD, whose disease phenotypes were found to be linked to chromosome 5 p15.1 (locus symbol CCAL2), were screened by direct sequencing for mutations in ANKH, a gene in the CCAL2 candidate interval that has been shown to harbor mutations in other families with CPPD. Observed sequence variants were confirmed by antisense sequencing, and expression of the mutant allele was verified by reverse transcriptase-polymerase chain reaction amplification of messenger RNA followed by direct sequencing.

Results. The two US families displayed the same mutation at position 5 of the ANKH gene product (P5T). All affected members were heterozygous for the P-to-T variant, and the mutation was not seen in 204 control alleles. The two families displayed distinct disease haplotypes, suggesting that they were unrelated to each other.
\end{abstract}

\footnotetext{
Dr. Williams' work was supported by NIH/National Institute of Arthritis and Musculoskeletal and Skin Diseases grant AR-44360.

${ }^{1}$ Charlene J. Williams, PhD, Gina Bonavita, BS, Shelly Peariso, MS: Thomas Jefferson University, Philadelphia, Pennsylvania; ${ }^{2}$ Adrian Pendleton, MD, Anne E. Hughes, PhD: The Queen's University of Belfast, Belfast, Northern Ireland; ${ }^{3}$ Antonio J. Reginato, MD: Robert Wood Johnson Medical School, Camden, New Jersey; ${ }^{4}$ Michael Doherty, MD: City Hospital, Nottingham, UK; ${ }^{5}$ Daniel J. McCarty, MD, Lawrence M. Ryan, MD: Medical College of Wisconsin, Milwaukee.

Address correspondence and reprint requests to Charlene J. Williams, PhD, Thomas Jefferson University, 233 South Tenth Street, BLSB508, Philadelphia, PA 19107. E-mail: charlene.williams@ jefferson.edu.

Submitted for publication March 3, 2003; accepted in revised form April 22, 2003
}

Conclusion. These observations represent the fourth and fifth families with heritable CPPD whose disease phenotypes are linked to the CCAL2 locus and who have missense mutations in the amino terminus of ANKH. This same position (P5) was the site of a missense mutation in an Argentinean family of northern Italian ancestry; however, the sequence variant in that family generated a P5L mutation. The distinct disease haplotypes among the 3 families with P5 mutations suggest that the mutations arose independently and that the evolutionarily conserved P5 position of ANKH may represent a hot spot for mutation in families with autosomal-dominant CPPD.

Calcium pyrophosphate dihydrate crystal deposition disease (CPPD) is a disease of articular cartilage that is radiographically characterized by the deposition of calcium-containing crystals in the joint $(1,2)$. When it occurs as a familial disorder, it is usually inherited in an autosomal-dominant manner, and affected family members may display symptoms of disease as early as their third decade of life. Several families with multiple generations of affected members have been studied by parametric genetic linkage analysis, and a locus on the short arm of chromosome 5 (locus symbol CCAL2, MIM $118600)$ has been linked to the disorder $(3,4)$.

Ho et al (5) described the cloning of a gene that was responsible for a recessive phenotype in the ank (progressive ankylosis) mouse. The human homolog for this gene, ANKH (MIM 605145), was located in a region syntenic with the mouse chromosomal assignment on human chromosome 5p. Because of its location in the CCAL2 candidate interval and its reported function as a regulator of inorganic pyrophosphate (PPi) transport (5), ANKH became an obvious positional candidate 
gene for CPPD. Mutation analyses of ANKH in the 3 families for which linkage analyses were performed $(3,4)$ discovered 3 distinct mutations at the amino terminus of the coding region for the gene. In a British family with CPPD, a base substitution just upstream of the translation start codon introduced a new translation initiation point that, in in vitro analysis, resulted in the translation of a protein from the mutant allele that was 4 amino acids longer than that translated from the normal allele (6). In a French family with CPPD originally described by Gaucher et al (7), a missense mutation in the second exon of the ANKH gene resulted in an M48T heterozygous sequence variant in all affected family members (6). Finally, in an Argentinean family of northern Italian descent, a base substitution in the first exon of the gene resulted in a P5L missense mutation in affected members (8).

In the present study, we observed a new missense mutation at amino acid position 5 of the ANKH gene product. In two US families of British and German/Swiss ancestry, the missense mutation was a transversion that changed the first basepair of the proline codon (CCG) to a threonine (ACG).

\section{PATIENTS AND METHODS}

Family studies and isolation of genomic DNA and total RNA. The two US families with radiographically confirmed CPPD consisted of 9 affected members and 15 unaffected members from 3 generations. In family US-A, the proband, member III:8, had had numerous episodes of pseudogout since her third decade of life; this was also the case for other affected members of this kindred, including members II:6, III:2, III:3, and III:12. All affected members also reported having chronic joint symptoms and developed osteoarthritis later in life. Radiographic evidence of chondrocalcinosis demonstrated involvement of both fibro- and hyaline cartilage and mainly involved the knees and feet. There was no evidence of extraarticular calcification. Calcium pyrophosphate dihydrate crystals were microscopically identified in joint effusions from affected members.

Details concerning the phenotype of family US-B were previously described (9). Affected members of this family had radiographically confirmed degenerative joint disease, and about one-half of the affected members had acute episodes of arthritis superimposed on their chronic joint symptoms. Most affected members demonstrated polyarticular disease with involvement of both fibro- and hyaline cartilage. In rare cases, patients in the family were asymptomatic despite having radiographic evidence of chondrocalcinosis. This family was also examined for pyrophosphohydrolase activity and PPi content in cultured skin fibroblasts of some affected members (10).

For genotype analyses and mutation screening, genomic DNA was extracted from peripheral blood samples obtained from family members using the PureGene DNA Isolation Kit (Gentra Systems, Minneapolis, MN). The project to define the molecular basis for familial chondrocalcinosis was approved by the Institutional Review Board at Thomas Jefferson University. For reverse transcriptase-polymerase chain reaction (RT-PCR) analyses, total RNA was extracted from peripheral blood leukocytes using the QIAamp RNA Blood Mini Kit (Qiagen, Valencia, CA).

Linkage analyses. Genotyping of family members using fluorescently labeled polymorphic markers from the CCAL2 region (D5S817, D5S1991, D5S1954, D5S1963, D5S416, D5S1997) was performed, and PCR products were visualized on an ABI 373 sequencer and analyzed with GeneScan software (Applied Biosystems, Foster City, CA). Twopoint linkage analyses were performed with the FASTLINK versions of the LINKAGE package of programs as previously described (4) under an autosomal-dominant mode of inheritance. Haplotypes for family members were manually derived from inspection of genotype data.

Sequence analysis of ANKH. All 12 exons of the ANKH gene were sequenced from genomic DNA of probands from each family and several unaffected and 102 unrelated, racially matched controls. Primers for amplification by the PCR were designed to include at least $100 \mathrm{bp}$ of flanking intronic sequence. Sequencing was performed by automated dideoxynucleotide terminator chemistry on an ABI 377 sequencer. Some PCR products were subcloned using the TA cloning vector system (Invitrogen, Carlsbad, CA), and clones containing inserts were subjected to DNA sequencing using vector sequences as primers. Sequence variants were confirmed by sequencing the products with putative variants with the antisense primer.

The primers for the amplification of genomic DNA for exon 1 that harbored the sequence variants were as follows: ANK -248 (sense), 5'-GCAGATCTTTGTTGTGTGGG-3'; ANK 85C (antisense), 5'-AGTCGATGGCTATGTTGGTG$3^{\prime}$. For improved resolution of PCR products, some reactions were subjected to a second round of PCR using a nested antisense primer: ANK 55C, 5'-GCACCAAGAACCGGATCAGG- $3^{\prime}$. The primer numbers $85 \mathrm{C}$ and $55 \mathrm{C}$ denote the positions of the primers on the complementary (C) strand of exon 1; the -248 sense primer refers to the position of this primer in the $5^{\prime}$-untranslated region $\left(5^{\prime}\right.$-UTR) (where position 1 is A of the ATG initiation codon). PCR reactions were performed for 35 cycles using an annealing temperature of $60^{\circ} \mathrm{C}$ and including 5\% DMSO as an adjunct to aid in denaturation of the GC-rich region that resides $5^{\prime}$ of the initiation codon. The outside and nested primer pairs generated PCR products of $334 \mathrm{bp}$ and $304 \mathrm{bp}$, respectively.

For RT-PCR analyses, RNA was used as template for the generation of complementary DNA (cDNA) and was subjected to the PCR using the ThermoScript RT-PCR system (Invitrogen) using the following primers: ANK -37 (sense), 5'-CAGCAGATGTGTGTGGGGTCAG-3'; ANK 497C (antisense), 5'-GATTGAGGCACATCCCACCAGG-3'; ANK 414C antisense (nested), 5'-GAAAGGCGGCGAGGTACAGGAA-3'. The primer numbers $497 \mathrm{C}$ and $414 \mathrm{C}$ denote the cDNA positions of the primers on the $\mathrm{C}$ strand of exons 4 and 3 , respectively; the -37 sense primer refers to the position of this primer in the $5^{\prime}$-UTR (where position 1 of the cDNA is A of the ATG initiation codon). PCR amplifications of reversetranscribed cDNA were performed for 35 cycles under standard conditions at an annealing temperature of $58^{\circ} \mathrm{C}$. The 
outside and nested primer pairs generated PCR products of $535 \mathrm{bp}$ and $452 \mathrm{bp}$, respectively.

\section{RESULTS}

The pedigrees of both US families are depicted in Figure 1. Genetic linkage analyses and haplotype reconstructions were performed on both families and these analyses confirmed that the disease phenotypes in the families were linked to the CCAL2 locus on chromosome 5p15.1 (data not shown).

In light of previous observations of mutations in

\section{Family US-A}


Figure 1. Pedigrees of the two US families described in the present report. All individuals shown were screened for mutations in ANKH. Closed symbols represent individuals affected with calcium pyrophosphate dihydrate crystal deposition disease (CPPD). Open symbols represent unaffected individuals. Arrows indicate probands. Members IV:1 and IV:3 of family US-A and member III: 1 of family US-B carry the disease haplotype and the P5T mutation in ANKH, but were too young at the time of DNA sample collection to display the CPPD phenotype.
ANKH in families with CPPD whose disease phenotypes were linked to the $5 \mathrm{p} 15.1$ chromosomal interval $(6,8)$, ANKH was screened for disease-causing mutations in genomic DNA from affected and unaffected members of each family by direct sequence analysis. Several neutral polymorphisms were observed that included a third base variant at amino acid position 98 (GCT $\rightarrow$ GCC) and a base substitution in IVS10 at position +33 with respect to the end of exon 10 in family US-A. However, an amino acid change in exon 1 was noted in both families. This change was generated from a point mutation in one allele of the exon to change a proline (CCG) to a threonine (ACG) (Figure 2A). The presence of the mutation was confirmed by antisense sequencing of the genomic DNA PCR product (data not shown), and its presence in mature transcripts of ANKH was confirmed by RT-PCR analysis of messenger RNA isolated from peripheral blood lymphocytes of 2 affected members of family US-A. Figure 2B illustrates antisense sequencing of cloned mutant and normal transcript alleles from member III:8 of family US-A.

Table 1 lists the mutations in ANKH that have now been described in families with CPPD whose disease phenotypes have been linked to chromosome 5p15.1. The reported mutations are clustered in the amino terminus of the coding region of ANKH.

\section{DISCUSSION}

Although the deposition of calcium-containing crystals in articular cartilage (i.e., chondrocalcinosis) is a common finding that is frequently associated with advanced osteoarthritis, the familial manifestation of this disorder is relatively rare. In its most severe form, the disorder may occur as an acute-onset disease resulting in considerable pain and disability. Ultimately, patients display significant degenerative joint disease.

The most commonly observed crystals in familial chondrocalcinosis are calcium pyrophosphate dihydrate crystals, and familial calcium pyrophosphate dihydrate deposition has been linked to loci on chromosomes $8 \mathrm{q}$ (locus symbol CCAL1, MIM 600668; ref. 11) and 5p (locus symbol CCAL2, MIM 118600; refs. 3 and 4). Among the positional candidates in the $5 \mathrm{p}$ locus was the human homolog of a mouse mutation called progressive ankylosis (ank). Recessive mutant mice (ank/ank) display calcification of numerous joints (in the form of deposition of hydroxyapatite) and arthritis $(12,13)$. The ank gene codes for a protein with putative multipass transmembrane domains, and this protein may function 
A

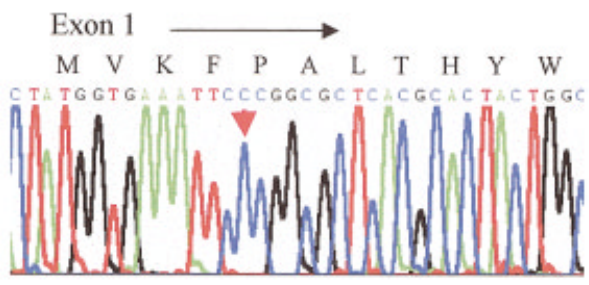

Unaffected

B

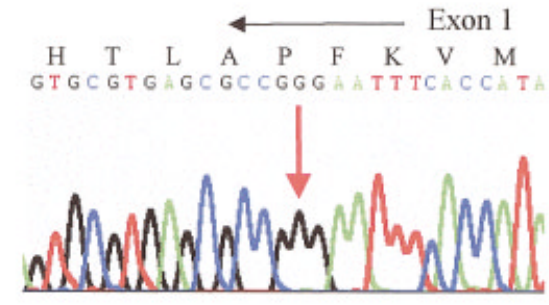

Normal Allele



Affected

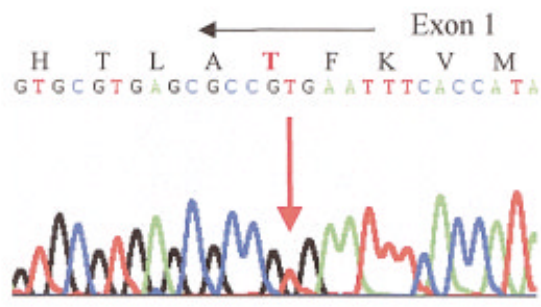

Mutant Allele

Figure 2. A, Genomic DNA sequence from polymerase chain reaction (PCR) analysis of exon 1 from one unaffected family member and from one affected family member of kindred US-A. B, Reverse transcriptase (RT)-PCR analysis of an affected member of kindred US-A. RT-PCR products were cloned, and the antisense sequence is depicted.

as an ion channel for the transport of PPi across the cell membrane (5).

Although familial CPPD demonstrates a crystal type and other phenotypic features that are somewhat different from those of the mouse mutant, heterozygous

Table 1. ANKH mutations in families with calcium pyrophosphate dihydrate crystal deposition disease whose disease phenotypes have been linked to chromosome $5 \mathrm{p} 15.1^{*}$

\begin{tabular}{|c|c|c|c|c|c|}
\hline Family & Exon & $\begin{array}{c}\text { cDNA } \\
\text { position } \dagger\end{array}$ & $\begin{array}{l}\text { Amino } \\
\text { acid } \\
\text { position† }\end{array}$ & $\begin{array}{l}\text { Type of } \\
\text { mutation }\end{array}$ & Ref. \\
\hline British & $5^{\prime}$-UTR & -11 & NA & $\begin{array}{l}\text { Base } \\
\text { substitution } \\
\text { (INS+4) }\end{array}$ & 6 \\
\hline French & 2 & 143 & 48 & Missense & 6 \\
\hline Argentinean & 1 & 14 & 5 & Missense & 8 \\
\hline US-A & 1 & 13 & 5 & Missense & $\begin{array}{r}\text { Present } \\
\text { study }\end{array}$ \\
\hline US-B & 1 & 13 & 5 & Missense & $\begin{array}{r}\text { Present } \\
\text { study }\end{array}$ \\
\hline
\end{tabular}

* $\mathrm{cDNA}=$ complementary DNA; 5'-UTR $=5^{\prime}$-untranslated region; $\mathrm{NA}=$ not applicable; INS $+4=$ insertion of 4 amino acids.

$\dagger$ With respect to A of the ATG initiation codon equal to cDNA position 1.

$\ddagger$ With respect to methionine at this position equal to amino acid 1 . mutations in ANKH have now been observed in several families with CPPD, including the two new families described here. The mutations that we have described are in contrast to that reported for an Argentinean family of northern Italian ancestry, in which the second position of the P5 codon (CCG) underwent a transition mutation to generate a leucine (CTG; ref. 8). Both US families displayed unique haplotypes in the region of chromosome $5 p$ that harbors the ANKH gene (data not shown); these haplotypes were distinct from that observed for the Argentinean kindred. Taken together, these observations suggest that the P5 mutations in all 3 families arose independently, and that this position in ANKH may be a hot spot for mutation.

The decisive proof that a mutation in a gene gives rise to the genetic disorder under analysis must reside at the level of alteration of protein function. Previous in vitro functional studies of the mouse nonsense mutation (a G-to-T transversion that substitutes a stop codon for a glutamine) by Ho et al (5) demonstrated that expression of that recessive mutation results in a significant increase in intracellular PPi levels and a concomitant reduction in extracellular PPi. Since PPi is a potent 
inhibitor of hydroxyapatite deposition, it has been hypothesized that a decrease in extracellular PPi (loss of function) might promote crystal deposition in the joints of the mutant ank/ank mouse (5). Interestingly, similar in vitro functional analyses of two of the human mutations did not significantly affect intracellular levels of PPi (6). Although measurements of extracellular PPi levels were not performed, it was hypothesized that the human mutations were likely to result in small increases in extracellular PPi levels (gain of function) (6), consistent with proposed models of calcium pyrophosphate dihydrate crystal deposition resulting from increased extracellular levels of PPi (for review, see ref. 14).

Future analyses of the ANKH mutations described here and elsewhere in both in vitro and in vivo systems will enable the elucidation of derangement in the function of ANKH that leads to abnormal PPi metabolism resulting in the pathologic deposition of calcium pyrophosphate dihydrate crystals in the joints of affected family members. Ultimately, the extension of these studies to forms of chondrocalcinosis that display nongenetic etiologies may assist in identifying and developing effective therapeutic modalities for many more patients.

\section{ACKNOWLEDGMENTS}

The authors are grateful to Rodney McGrath for excellent technical assistance and to the families for their participation in this study.

\section{REFERENCES}

1. Ryan LM, McCarty DJ. Calcium pyrophosphate crystal deposition disease; pseudogout; articular chondrocalcinosis. In: McCarty DJ, Koopman WJ, editors. Arthritis and allied conditions. 12th ed. Philadelphia: Lea \& Febiger; 1993. p. 1835-55.
2. Doherty M, Dieppe P. Clinical aspects of calcium pyrophosphate dihydrate crystal deposition. Rheum Dis Clin North Am 1988;14: 395-414.

3. Hughes AE, McGibbon D, Woodward E, Dixey J, Doherty M. Localisation of a gene for chondrocalcinosis to chromosome $5 \mathrm{p}$ Hum Mol Genet 1995;4:1225-8.

4. Andrew LJ, Brancolini V, Serrano de la Pena L, Devoto M, Caeiro F, Marchegiani R, et al. Refinement of the chromosome 5p locus for familial calcium pyrophosphate dihydrate deposition disease. Am J Hum Genet 1999;64:136-45.

5. Ho A, Johnson M, Kingsley DM. Role of the mouse ank gene in control of tissue calcification and arthritis. Science 2000;289: 265-70.

6. Pendleton A, Johnson MD, Hughes A, Gurley KA, Ho AM, Doherty M, et al. Mutations in ANKH cause chondrocalcinosis. Am J Hum Genet 2002;71:933-40.

7. Gaucher A, Faure G, Netter P, Purel J, Raffoux C, Streiff F, et al. Hereditary diffuse articular chondrocalcinosis: dominant manifestation without close linkage with the HLA system in a large pedigree. Scand J Rheumatol 1977;6:217-21.

8. Williams CJ, Zhang Y, Timms A, Bonavita G, Caeiro F, Broxholme $\mathrm{J}$, et al. Autosomal dominant familial calcium pyrophosphate dihydrate deposition disease (CPPDD) is caused by mutation in the transmembrane protein ANKH. Am J Hum Genet 2002;71:985-91.

9. Perry E, Overholt EL, Newcomer KL. Familial occurrence of chondrocalcinosis (pseudogout syndrome). Wis Med J 1969;68: 321-4.

10. Ryan LM, Wortmann RL, Karas B, Lynch MP, McCarty DJ. Pyrophosphohydrolase activity and inorganic pyrophosphate content of cultured human skin fibroblasts: elevated levels in some patients with calcium pyrophosphate dihydrate deposition disease. J Clin Invest 1986;77:1689-93.

11. Baldwin CT, Farrer LA, Adair R, Dharmavaram R, Jimenez S, Anderson L. Linkage of early-onset osteoarthritis and chondrocalcinosis to human chromosome 8q. Am J Hum Genet 1995;56: 692-7.

12. Sweet HO, Green MC. Progressive ankylosis, a new skeletal mutation in the mouse. J Hered 1981;72:87-93.

13. Hakim FT, Cranley R, Brown KS, Eanes ED, Harne L, Oppenheim JJ. Hereditary joint disorder in progressive ankylosis (ank/ ank) mice. I. Association of calcium hydroxyapatite deposition with inflammatory arthropathy. Arthritis Rheum 1984;27:1411-20.

14. Ryan LM, McCarty DJ. Understanding inorganic pyrophosphate metabolism: toward prevention of calcium pyrophosphate dihydrate crystal deposition. Ann Rheum Dis 1995;54:939-41. 